\title{
Enamel matrix derivative for direct pulp capping
}

\author{
Abstracted from \\ Garrocho-Rangel A, Flores H, Silva-Herzog D, Hernandez-Sierra F, Mandeville P, Pozos-Guillen AJ. \\ Efficacy of EMD versus calcium hydroxide in direct pulp capping of primary molars: a randomized controlled clinical trial. \\ Oral Surg Oral Med Oral Pathol Oral Radiol Endod 2009; 107: 733-738 \\ Address for correspondence: Dr Amaury de Jesús Pozos Guillén, Facultad de Estomatología, \\ Universidad Autónoma de San Luis Potosí, Av. Dr. Manuel Nava \#2, Zona Universitaria, C.P. 78290, \\ San Luis Potosí, México. E-mail: apozos@uaslp.mx
}

\section{Question: Is enamel matrix derivative as effective as calcium hydroxide for direct pulp capping of primary molars?}

\footnotetext{
Design A split-mouth randomised controlled trial (RCT) was conducted.

Intervention Standard noncarious pulp exposures were treated with either enamel matrix derivative (EMD) or calcium hydroxide and restored with a preformed metal crown (PMC). Patients were followed up at 1,6 and 12 months.

Outcome measures The appearance of any of the following was considered to signify treatment failure: internal dentin resorption, spontaneous pain, gingival abscess (sinus tract), external root resorption, or pathologic mobility.

Results In total, 90 direct pulp capping (DPC) treatments were performed (45 in the experimental group and 45 in the control group) and followed for 12 months. There were 88 successful treatments at the end of this period, with only two failures (one in each study group) Conclusions Both capping materials showed a similar effectiveness in this pulp procedure with a postoperative observation time of 12 months. On the basis of this study, we recommend the use of DCP treatment on primary molars as a standard technique.
}

\section{Commentary}

In the recent past, DPC for managing carious primary teeth has fallen out of favour. The 2006 British Society of Paediatric Dentistry guidelines on pulp therapy ${ }^{1}$ state that, "this approach has limited application and is generally not recommended for primary molars" and "no studies of good quality are available". There would also appear to be lack of agreement on the technique, with a recent study of UK and Irish dental schools finding no uniformity in techniques taught for DPC. ${ }^{2}$

It would thus initially seem helpful to have an RCT such as this, producing evidence in an area where it is lacking and where there may be confusion. This is a high quality split-mouth RCT, although one could quibble that the CONSORT guidelines are not followed as stated, with there being no explanation for the 11 excluded patients. On further reading of this paper, however, it is difficult to see the relevance to current clinical practice. Looking more closely at the clinical situation and the techniques used in this trial, it can be seen that participants had matched "deeply decayed primary molars" on each side of the mouth, but with no clinical signs or symptoms of "pulpitis or pulp necrosis". The authors state that peripheral caries was removed and, "a standard and noncarious 1-mm pulp exposure was created [my italics] with a \#3 carbide round bur". After irrigation and haemostasis, calcium hydroxide was placed over the pulp in the control group and EMD in the experimental group followed by placement of a PMC.

This trial showed DPC achieve good results at 1 year, regardless of whether calcium hydroxide or EMD was used. The first explanation for the success of the DPC given by the authors is the absence of inflammation in the exposed pulpal tissue, something they, "meticulously observed during diagnostic and treatment phases". Might it be, however, that the pulps were relatively healthy, and that the DPC was unnecessary? It should be noted that the teeth in both groups were immediately restored with a PMC. Pulpotomised teeth, restored with PMC, have repeatedly been shown to outperform those restored with other materials ${ }^{3-5}$ regardless of the pulpal medicament used. This success is generally attributed to PMC providing a good coronal seal, and might, in part, explain the high success rates for calcium hydroxide in this study.

What is not clear is why it is still considered a reasonable treatment option to directly disrupt the dental pulp in primary teeth which, although they show deep caries radiographically, are asymptomatic. These lesions can be managed successfully with other less invasive techniques such as an indirect pulp cap ${ }^{6}$ (90\% success after 4 years), stepwise caries removal ${ }^{7}$ (95\% success at 1 year), partial caries remov- 


\section{CARIES}

$\mathrm{al}^{8}$ (100\% at 1 year), or the Hall Technique ${ }^{9}$ (97\% success at 2 years although only $42 \%$ of lesions were more than halfway into dentine).

Although this well-conducted, high-quality trial found very high success rates for both treatments, the clinician should consider whether DPC is a technique that is applicable for practice today, and it might be suggested that, for deep carious lesions in primary molar teeth with no clinical or radiographic signs of pulpitis or pulp necrosis, a less invasive alternative to DPC should be considered.

\section{Nicola Innes}

Preventive and Children's Dentistry Section, Dundee Dental Hospital and School, Dundee, Scotland, UK

\section{Practice points}

- For primary molars with deep caries radiographically, but which have no clinical or radiographic signs of pulpitis or pulp necrosis:

- DPC has been shown to be a successful technique where there is not carious exposure.

- Given the high treatment success rates of other techniques which are less invasive (indirect pulp cap, stepwise caries removal, partial caries removal or the Hall Technique), the clinician may wish to consider these options for asymptomatic primary molars with deep caries.
1. Rodd HD, Waterhouse PJ, Fuks AB, Fayle SA, Moffat MA. British Society of Paediatric Dentistry.Pulp therapy for primary molars. Int J Paediatric Dentistry 2006; 16 (suppl. 1): S15-S23.

2. Ni Chaollai A, Monteiro J, Duggal MS. The teaching of management of the pulp in primary molars in Europe: a preliminary investigation in Ireland and the UK. Eur Archive Paediatr Dent 2009; 10: 98-103.

3. Holan G, Fuks A B, Ketlz N. Success rate of formocresol pulpotomy in primary molars restored with stainless steel crown vs amalga. Pediatr Dent 2002; 24: 212-216.

4. Farooq NS, Coll JA, Kuwabara A, Shelton P. Success rates of formocresol pulpotomy and indirect pulp therapy in the treatment of deep dentinal caries in primary teeth. Pediatr Dent 2000; 22: 278-286.

5. Sonmez D, Duruturk L. Success rate of calcium hydroxide pulpotomy in primary molars restored with amalgam and stainless steel crowns. Br Dent J 2009; 208: 408-409.

6. Marchi JJ, de Araujo FB, Fröner AM, Straffon LH, Nör JE. Indirect pulp capping in the primary dentition: a 4 year follow-up study. / Clin Pediatr Dent 2006; 31: 68-71.

7. Magnusson BO, Sundell SO. Stepwise excavation of deep carious lesions in primary molars. J Int Assoc Dent Children 1977; 8: 36-40.

8. Ribeiro CCC, Baratieri LN, Perdigão J, Baratieri NMM, Ritter AV. A clinical, radiographic, and scanning electron microscopic evaluation of adhesive restorations on carious dentin in primary teeth. Quintessence Int 1999; 30: 591-599.

9. Innes NP, Evans DJ, Stirrups DR. The Hall Technique: a randomized controlled clinical trial of a novel method of managing carious primary molars in general dental practice: acceptability of the technique and outcomes at 23 months. BMC Oral Health 2007 Dec 20;7: 18

Evidence-Based Dentistry (2010) 11, 45-46. doi:10.1038/sj.ebd.6400719 